\title{
Mutual Impacts and Interactions of Antibiotic Resistance Genes, Microcystin Synthetase Genes, Graphene Oxide, and Microcystis Aeruginosa in Synthetic Wastewater
}

\section{Shichao Wu}

Shanghai Institute of Technology

Xiyan Ji ( $\nabla$ xiyanji@sit.edu.cn )

Shanghai Institute of Technology

Xin Li

Shanghai Institute of Technology

Jing Ye

Shanghai Institute of Technology

\section{Wenwu Xu}

Shanghai Institute of Technology

\section{Rui Wang}

Shanghai Majorbio. Tec. Ltd

\section{Meifang Hou}

Shanghai Institute of Technology

\section{Research Article}

Keywords: Interactions, Antibiotic resistance genes, Microcystin synthetase gene, Microcystic aeruginosa, Graphene oxide

Posted Date: May 21st, 2021

DOl: https://doi.org/10.21203/rs.3.rs-322632/v1

License: (9) This work is licensed under a Creative Commons Attribution 4.0 International License. Read Full License

Version of Record: A version of this preprint was published at Environmental Science and Pollution Research on August 16th, 2021. See the published version at https://doi.org/10.1007/s11356-021-15627- 


genes, graphene oxide, and Microcystis aeruginosa in synthetic wastewater Shichao $\mathrm{Wu}^{1}$, Xiyan $\mathrm{Ji}^{1 *}$, Xin $\mathrm{Li}^{1}$, Jing $\mathrm{Ye}^{2}$, Wenwu Xu ${ }^{3}$, Rui Wang ${ }^{4}$, Meifang $\mathrm{Hou}^{1 *}$

${ }^{1}$ School of Ecological Technology and Engineering, Shanghai Institute of Technology, Shanghai 5 201418, P.R. China

${ }^{2}$ School of Chemical and Environmental Engineering, Shanghai Institute of Technology, Shanghai 201418, P.R. China

${ }^{3}$ School of Railway Transportation, Shanghai Institute of Technology, Shanghai 201418, P.R. China *Corresponding authors: 


\section{Abstract}

The physiological impacts and interactions of ARGs abundance, microcystin synthetase genes expression, GO, and M. aeruginosa in synthetic wastewater were investigated. The results demonstrated that the absolute abundance of sull, sul2, tet $W$, and tetM in synthetic wastewater dramatically increased to $365.2 \%, 427.1 \%, 375.2 \%$, and $231.7 \%$, respectively, when the GO concentration was $0.01 \mathrm{mg} / \mathrm{L}$. Even more interesting is that the sum gene copy numbers of $m c y A-J$ also increased to $243.2 \%$. The appearance of GO made the significant correlation exist between ARGs abundance and mcyA-J expression. Furthermore, M. aeruginosa displayed better photosynthetic performance and more MCs production at $0.01 \mathrm{mg} / \mathrm{L}$ GO. There were 65 pairs of positive correlations between the intracellular differential metabolites of $M$. aeruginosa and the abundance of sull, sul2, tetM, and tetW with various GO concentrations. The GO will impact the metabolites and metabolic pathway in M. aeruginosa. The metabolic changes impacted the ARGs, microcystin synthetase genes, and physiological characters in algal cells. Furthermore, there were complex correlations among sull, sul2, tetM, tetW, mcyA-J, MCs, photosynthetic performance parameters, and ROS. The different concentration of GO will aggravate the hazards of $M$. aeruginosa by promoting the expression of $m c y A-J$, producing more MCs, simultaneously, it may cause the spread of ARGs.

Keywords: Interactions, Antibiotic resistance genes, Microcystin synthetase gene, Microcystic aeruginosa, Graphene oxide 


\section{Introduction}

Antibiotic resistance genes (ARGs) pollution has become knotty problem that has attracted much attention around the world (Conley et al. 2009). The overuse of antibiotics in medicine, cultivation, and aquaculture field has caused the accumulation of ARGs in aquatic environment (Komijani et al. 2021). The ARGs have been detected in many water bodies in China, especially ARGs of sulfonamides and tetracyclines are ubiquitous and with high concentration (Sun et al. 2017). The average level of ARGs in natural waters reached $1.2 \times 10^{8}$ gene copies $/ \mathrm{mL}$ (Sun et al. 2017). There are not only large amounts of ARGs remaining in general water bodies, but also the problem of Microcystis aeruginosa (M. aeruginosa) should not be ignored. The overgrowth of M. aeruginosa not only caused harmful algae bloom but also produced very potent microcystins (MCs) which can stimulate oxidative stress of the cell, which would produce a large amount of reactive oxygen species (ROS) (Chen et al. 2016, McLellan \&Manderville 2017). The ROS would promote the change of cell permeability, which accelerate the release of intracellular substances (Jiang et al. 2021). The increase in membrane permeability is one of the fundamental reasons for increasing the transfer efficiency of ARGs (Guo et al. 2021, Lu et al. 2020b, Sun et al. 2018). And then, to make matters worse, the graphene oxide (GO) would inevitably be released into the aquatic environment with its extensive application (Yang et al. 2019, Zhu et al. 2019). The presence of GO might have a certain impact on the growth of $M$. aeruginosa, microcystin synthetase genes, and MCs production (Yang et al. 2019). Aquatic environment is an important medium for the release and diffusion of MCs, ARGs, and GO. These pollutants can invade the human food chain by the water cycle, posing a serious threat to the aquatic ecological environment and human health (Avant et al. 2019, Jiang et al. 2020).

It is known that the pollutants in natural water bodies are very complicated, and there are many kinds of pollutants such as ARGs, M. aeruginosa, and nano-pollutants (Rzymski et al. 2020). The GO might affect the microcystin synthetase genes expression and MCs production when its concentration reaches a certain level (Wang et al. 2020a, Yin et al. 2020). People formerly believed 
that the abuse of antibiotics was the main reason for global accumulation and spread of ARGs (Sola 2020). However, more and more studies have shown that natural-occurring substances and some kinds of nano-pollutants in the aquatic environment can promote the spread of ARGs (Sun et al. 2021). Studies have shown that extractive of M. aeruginosa and pure MCs and nanometer materials can cause the spread of ARGs in aquatic environment (Fan et al. 2021, Xu et al. 2021). Some researchers have inferred that MCs and nanometer materials might change the permeability and surface functional groups of microbial cells and accelerate the rate which ARGs genetic material enters cells (Fan et al. 2021).

MCs are synthesized by the megazyme complex through non-ribosomal pathways (Yang et al. 2015). This type of complexus includes peptide synthase, polyketide synthase and some other modified enzymes (Wei et al. 2020). By sequencing the gene cluster encoding synthase, it was found that the gene cluster contained a type of mixed non-ribosomal peptide synthetase genes including $m c y A, m c y B, m c y C, m c y D, m c y E, m c y F, m c y G, m c y H, m c y I$ and $m c y J$ (Lu et al. 2020a). Simultaneously, nano-pollutants in aquatic environment will also affect the production of MCs. In the presence of GO, the transcription levels of the synthetase genes $m c y A, m c y B$ and $m c y D$ are significantly increased (Grasso et al. 2020). Therefore, what can be inferred is that although the production of MCs is determined by the genes in the microcystin-producing cells, the nano-pollutants such as GO in environment can also regulate their gene expression, thereby affecting the synthesis of MCs. The presence of MCs may increase the abundance of ARGs, and the GO in the aquatic environment might make the transcription of MCs synthase genes increase. While, there is still no result that can effectively verify this inference, this work is trying to prove this. What are the mutual impacts and interactions of ARGs, microcystin synthetase genes, MCs, GO, and M. aeruginosa, the researches on this aspect were currently rare.

The abundance changes of ARGs including sull, sul2, tet $W$, tetM and the gene copy numbers of MCs microcystin synthetase genes including $m c y A, m c y B, m c y C, m c y D, m c y E, m c y F, m c y G$, $m c y H, m c y I, m c y J$ in GO-exposed M. aeruginosa with different concentrations were investigated in this study. Meanwhile, the correlativity between ARGs abundance and mcyA-J expression quantity was evaluated. Moreover, the effect of GO with different concentrations on the 
ultrastructure, photosynthesis, metabonomics characters of $M$. aeruginosa were also studied. These results will reveal the mutual impacts and interactions of ARGs, microcystin synthetase genes, graphene oxide, and Microcystis aeruginosa in synthetic wastewater, which will provide some basics for the studies of multi-component pollutants in aquatic environment.

\section{Materials and methods}

\subsection{Experimental design}

M. aeruginosa (FACHB-315) was purchased from the Institute of Wuhan Hydrobiology, Chinese Academy of Sciences and cultured in pH 7.0 BG11 medium (Table S1). The GO was purchased from the Chengdu Institute of Organic Chemistry, Chinese Academy of Sciences. The GO sheets diameter was $0.1-10 \mu \mathrm{m}$ in size with average thickness of $1.5 \mu \mathrm{m}$. The plasmids of ARGs including sull, sul2, tetW, tetM were prepared by Genesis Biotechnology Co., Ltd. The gene sequences of sull, sul2, tetW, tetM were listed in Table S2.

For the incubation experiment, photobioreactors as shown in Fig. 1 was used. The GO particles were dispersed in synthetic wastewater (Table S3) with initial concentrations of $0,0.01,0.1,1$, and $10 \mathrm{mg} / \mathrm{L}$, and for the control group, the GO concentration was $0 \mathrm{mg} / \mathrm{L}$. The GO concentration range was set close to that found in natural water (Zhao et al. 2020b). In these systems, GO particles had hydrodynamic diameters of $250-300 \mathrm{~nm}$ and zeta potentials ranges from -30 to 50 $\mathrm{mV}$, indicating that the GO particles had been stably dispersed in the synthetic wastewater at the four concentrations (Monteil et al. 2014). M. aeruginosa was inoculated at density of $1.0 \times 10^{5}$ cells $/ \mathrm{mL}$ and the reactors were placed in an illumination incubator (MGC-300A, China) at $28.0 \pm$ $0.5^{\circ} \mathrm{C}$ and $75 \%$ humidity. At the beginning $(0 \mathrm{~h})$ and after $0,24,48,96 \mathrm{~h}$ of incubation, samples were taken from each reactor and centrifuged at $8000 \times g$ for $10 \mathrm{~min}$. The supernatants were used for analyses of ARGs abundance, total nitrogen (TN), ammoniacal nitrogen $\left(\mathrm{NH}_{3}-\mathrm{N}\right)$, phosphate phosphorus $\left(\mathrm{PO}_{4}{ }^{3-}-\mathrm{P}\right)$, chemical oxygen demand (COD), and extracellular MCs (MC-LR and MC-RR). The precipitates were collected for intracellular MCs and reactive oxygen species (ROS) quantification, metabolic responses, $m c y A-J$ gene expression analyses, and transmission electron 
microscopy (TEM) observation. Only samples taken at the end of the experiment (96 h) from the control, 0.01 , and $10 \mathrm{mg} / \mathrm{L} \mathrm{GO}$ were used for metabonomic analysis.

\subsection{Measurement of ARGs abudance}

The ARGs abundances of sull, sul2, tet $W$, tet $M$ were measured by HT-qPCR. The Light Cycler 480 YSBR Green I Master was used as fluorochrome. A total of 14 pairs of primers were selected, including 4 ARGs primers, 10 pairs of microcystin synthetase genes primers (Table S2). The HR-qPCR reaction system consists of $12.5 \mu \mathrm{L}$ PCR reaction mixture with ROX reference dye, 0.5 $\mu \mathrm{L}$ (with concentration of $10 \mu \mathrm{mol} / \mathrm{L}$ ) forward and reverse primers, $10.5 \mu \mathrm{L}$ DNA-free water, and $10 \mu \mathrm{L}$ sample DNA. The operation steps of HT-qPCR were as shown as follows: (1) $50^{\circ} \mathrm{C}, 2 \mathrm{~min}$; (2) $95^{\circ} \mathrm{C}, 5 \mathrm{~min}$; (3) $95^{\circ} \mathrm{C}, 20 \mathrm{~s}$; (4) annealing for $30 \mathrm{~s}$; (5) $72^{\circ} \mathrm{C}, 30 \mathrm{~s}$; (6) plate read, repeat the temperature of (3)-(5); (7) melting curve analysis, between $60-95^{\circ} \mathrm{C}$, read every $0.2^{\circ} \mathrm{C}$ (Wu et al. 2020a).

\subsection{Measurement of algal photosynthetic response and growth rate}

The phytoplankton classification fluorometer (Phyto-PAM, Germany, WALZ) was used to measure the various parameters of chlorophyll fluorescence. The specific steps are as follows: (1) Start the Phyto Win software, place a certain amount of sample (the volume should be uniform each time) in a cuvette for $15 \mathrm{~min}$. (2)Start the instrument to determine the initial measurement fluorescence yield $\left(F_{0}\right)$, measure the maximum fluorescence yield $\left(F_{m}\right)$ after the saturation pulse at $4000 \mu \mathrm{mol} /\left(\mathrm{m}^{2} \cdot \mathrm{s}\right)$. (3) Calculate the maximum light energy conversion efficiency $\left(F_{v} / F_{m}\right)$. (4) Set the photochemistry intensity at $3000 \mu \mathrm{mol} /\left(\mathrm{m}^{2} \cdot \mathrm{s}\right)$ and irradiate for $1 \mathrm{~min}$ util the indicator light turns green, the initial fluorescence $\left(F_{s}\right)$ and maximum fluorescence $\left(F_{m}\right)$ were measured when the fluorescence value was stable. The measured chlorophyll fluorescence parameters are $F_{0}, F_{m}, F_{0}$, $F_{m}{ }^{\prime}, F_{s}$. The fluorescence parameters such as $F_{v} / F_{m}, F_{v} / F_{0}, E T R_{\max }$ were calculated as follows (Poudyal et al. 2019): 
137 Maximum light conversion efficiency Eq. (1): $\frac{F_{v}}{F_{m}}=\frac{F_{m}-F_{0}}{F_{m}}$

Maximum photochemical quantum yield Eq. (2): $\frac{F_{v}}{F_{0}}=\frac{F_{0}}{F_{m}-F_{0}}$

Efficiency of light energy conversion Eq. (3): $\varphi P S I I=\frac{F_{m}^{\prime}-F_{s}}{F_{m^{\prime}}}$

140 Quantum efficiency Eq. (4): Yield $=\frac{F_{m}^{\prime}-\frac{1}{\frac{1}{F_{q}}-\frac{1}{F_{m}}-\frac{1}{F_{m} \prime}}}{F_{m^{\prime}}}$

Photosynthetic electron transport Eq. (5): $E T R=\varphi P S I I \times D A R \times 0.5 \times 0.84$

The specific growth rate of algae is used to reflect the growth of $M$. aeruginosa. The formula is shown in Eq. (6):

$$
\mu=\frac{\ln \left(\frac{X_{n}}{X_{n-1}}\right)}{t_{n}-t_{n-1}}
$$

In Eq. (6): $X_{n}$ is for the cell density of $M$. aeruginosa at the end of the GO-exposure period $\left(t_{n}\right)$, $X_{n-1}$ is the cell density of M. aeruginosa at the GO-exposure period ( $\left.t_{n-1}\right)$ (Elser et al. 2007).

\subsection{N, P nutrients removal determination}

After the supernatants of samples were filtered through $0.44-\mu \mathrm{m}$ filters, the concentration of nitrogen and phosphorus nutrients including $\mathrm{TN}, \mathrm{NH}_{3}-\mathrm{N}, \mathrm{PO}_{4}{ }^{3-}-\mathrm{P}$, and $\mathrm{COD}$ were determined as described in their study (Ajayan et al. 2019).

\subsection{MCs quantification and microcystin synthetase genes expression measurement}

The MCs in the supernatants were extracted with Oasis HLB and determined by liquid chromatography-mass spectrometry (LC-MS). Intracellular MCs (MC-LR and MC-RR) extraction was performed as described in previous study (Pinheiro et al. 2016). The sample was extracted with $75 \%$ methyl alcohol at $25^{\circ} \mathrm{C}$ for $20 \mathrm{~min}$ while stirring. The homogenate was centrifuged $(10000 \times g, 10 \mathrm{~min})$ to remove the pellet. The MCs in the supernatant were eluted using $80 \%(\mathrm{v} / \mathrm{v})$ 
methyl alcohol, concentrated at $35^{\circ} \mathrm{C}$ (Pinheiro et al. 2016), purified, and quantified using HPLC (Agilent 1200, USA). A reversed phase column equipped with a guard column at $45^{\circ} \mathrm{C}$ was used. For $m c y A-J$ gene expression analysis, total RNA of M. aeruginosa was transcribed to cDNA for RT-qPCR analysis on a real-time PCR system (Thermo fisher, Step One Plus, USA). The qPCR amplification procedure was operated as Lee reported (Lee et al. 2020).

\subsection{TEM observation and ROS determination}

The algal cells of $M$. aeruginosa were added to $2.5 \%$ glutaraldehyde with the final concentration was $2.5 \%$, then fixed for $3 \mathrm{~h}$. Centrifuged at $5000 \times \mathrm{g}$, the supernatant was removed, and $0.1 \mathrm{~mol} / \mathrm{L}$ phosphate buffer was added to wash the samples for 3 times. Then $4 \%$ osmic acid was added to fix the algal cell. The samples were centrifuged at $5000 \times \mathrm{g}$ for $5 \mathrm{~min}$ after incubation overnight at $4^{\circ} \mathrm{C}$, then the supernatant was removed. The acetone solutions of different concentrations of $10 \%, 30 \%, 50 \%, 70 \%, 90 \%$ and $100 \%$ were used to dehydrate. Resin was used to embed, then the sample was sectioned (EMUC7, Lycra, Austria). The 3\% uranyl acetate and $2 \%$ lead citrate were used to stain. Finally, the samples were observed by transmission electron microscope (HT7700, Hitachi, Japan) (Soares et al. 2020). The ROS levels of samples were detected by ROS kit (ML Elisa0255, R\&D Systems, USA) according its operating manual.

\subsection{Metabonomic determination}

Extraction, derivatization and GC-MS detection process of metabolites were performed as the modified method of Weckwerth (Weckwerth et al. 2004). A certain amount of sample (Grinded in liquid nitrogen) was added in $1 \mathrm{~mL}$ pre-cooled extraction solution (volume ratio of methanol to water is 1:1) and $5 \mu \mathrm{L}$ internal standard substance. Then the mixture was vortexed for $3 \mathrm{~min}$. After centrifugation $(8000 \times \mathrm{g}, 5 \mathrm{~min}), 500 \mu \mathrm{L}$ supernatant was placed in liquid nitrogen for $30 \mathrm{~min}$, then the sample was freeze-dried. The $50 \mu \mathrm{L}$ methoxyammonium hydrochloride/pyridine solution (20 $\mathrm{mg} / \mathrm{mL}$ ) was added, kept reacting at $40^{\circ} \mathrm{C}$ for $60 \mathrm{~min}$. The $80 \mu \mathrm{L}$ N-methyl-N-(trimethylsilane) trifluoroacetamide (MSTFA) was added, then reacted $80 \mathrm{~min}$ at $40^{\circ} \mathrm{C}$. After centrifugation at $8000 \times \mathrm{g}$, for $10 \mathrm{~min}$, the supinate was used to detection and analyzed by GC-MS. 


\subsection{Statistical analysis}

The treatments and measurements were all performed in triplicate. Origin 8.5 was used for data processing for statistical analysis. The identification of metabolites was performed by the NIST database (2011). The metabolite data were normalized, then they were imported into SIMCA software (Version 11.5) for the PCA and PLS analysis. The HCE 3.5 software was used to perform hierarchical cluster analysis. The figures in this study were drawn by Graph pad Prisim 7.0.

\section{Results and discussion}

\subsection{Analysis of mutual impacts between ARGs and microcystin synthetase genes expressions}

The absolute abundance of the total ARGs including sull, sul2, tetW, tetM of GO-exposed $M$. aeruginosa systems at concentration of $0.01 \mathrm{mg} / \mathrm{L}$ was improved 4 times than that at concentration of $0 \mathrm{mg} / \mathrm{L}$, especially for sull, sul2. The highest abundance of sull and sul2 in GO-exposed $M$. aeruginosa system with concentration of $0.01 \mathrm{mg} / \mathrm{L}$ reached $4.14 \times 10^{11}$ copies/L. The total genes copies of microcystin synthetase genes including $m c y A-J$ reach up to $2.98 \times 10^{10}$ when the concentration of GO was $0.01 \mathrm{mg} / \mathrm{L}$. In order to explain the impacts between ARGs (sull, sul2, tet $M$, tet $Q)$ and microcystin synthetase genes (mcyA-J), the correlation analysis was performed and the results were shown in Fig. 2.

The Pearson correlation analysis was performed between the expression of sull, sul2, tetW, tetM and the intracellular mcyA-J of M. aeruginosa in the synthetic wastewater when GO with concentration of $0.01,0.1,1,10 \mathrm{mg} / \mathrm{L}$. The results demonstrated that there were 30 pairs, 30 pairs, 30 pairs, and 25 pairs of correlations $(p<0.05)$ between ARGs and $m c y A-J$ at $24 \mathrm{~h}, 48 \mathrm{~h}, 72 \mathrm{~h}, 96 \mathrm{~h}$, respectively. It can be inferred that there was a positive correlation between the abundance of ARGs and the expression of $m c y A-J$ when the GO was present. When the GO concentration is 0 , there is no correlation between the abundance of sull, sul2, tetM, tetW and mcyA-J, which further demonstrated that the presence of GO made the abundance of ARGs closely related to the expression of $m c y A-J$. Interestingly, when the concentration of GO was $0.01 \mathrm{mg} / \mathrm{L}$, the expression 
of mcyA-J was significantly increased $(P<0.05)$, and the MCs production was also significantly increased, and the expressions of sull, sul2, tetM, tetW were also increases significantly $(P<0.05)$. The presence of GO at the concentration of $0.01 \mathrm{mg} / \mathrm{L}$ made the positive correlation between ARGs (sull, sul2, tetM, tet $W$ ) abudance and $m c y A-J$ expression further enhanced. What would be mentioned in latter section was that the photosynthesis performance of M. aeruginosa and MCs production were promoted when the GO concentration was $0.01 \mathrm{mg} / \mathrm{L}$. It can be inferred that the presence of GO in aquatic environment will aggravate the overgrowth of $M$. aeruginosa, MCs production, and spread of ARGs to a certain extent (Pan et al. 2015, Wu et al. 2020b).

\subsection{Influence of GO on the N, P removal by M. aeruginosa}

The nitrogen and phosphorus nutrients including total nitrogen (TN), ammoniacal nitrogen $\left(\mathrm{NH}_{3}-\mathrm{N}\right)$, phosphate $\left(\mathrm{PO}_{4}{ }^{3-}-\mathrm{P}\right)$, and chemical oxygen demand (COD) removal by M. aeruginosa is closely related to the growth rate (Ma et al. 2014). The removal rates of $\mathrm{TN}, \mathrm{NH}_{3}-\mathrm{N}, \mathrm{PO}_{4}{ }^{3-}-\mathrm{P}$, and COD were $25 \%, 72 \%, 36.2 \%$, and $42.9 \%$, respectively, at $0.01 \mathrm{mg} / \mathrm{L} \mathrm{GO}$ exposure (Fig. 3), indicating that $0.01 \mathrm{mg} / \mathrm{L} \mathrm{GO}$-exposure can effectively stimulate and promote nutrients removal by M. aeruginosa from the growth environment (Aphale et al. 2015). Much smaller removals of TN, $\mathrm{NH}_{3}-\mathrm{N}, \mathrm{PO}_{4}{ }^{3-}-\mathrm{P}$, and COD were observed in the $10 \mathrm{mg} / \mathrm{L}$ GO treatment, which might be attributed to the negative effects of GO at high concentration on the photosynthetic rates of algal cells [40], as evident by the low $F_{v} / F_{m}$ and $E T R_{\max }$ demonstrated in Fig. 1. Simultaneously, high concentration of 10 mg/L GO inhibited nutrients removal by M. aeruginosa (Zhao et al. 2020a).

\subsection{Cellular impacts of M. aeruginosa and GO}

Significant effects $(p<0.05)$ of GO on photosynthesis of $M$. aeruginosa was observed during the GO-exposure period at concentrations of $0.01,0.1,1$, and $10 \mathrm{mg} / \mathrm{L}$, respectively. The different concentration of GO-exposure also affected the growth rate significantly $(p<0.05)$. The results indicated that the intracellular production and extracellular release of MCs in GO-exposed groups were higher than that in the control (without GO exposure). As shown in Fig. 4A, the intracellular 
groups during the whole exposure period. Simultaneously, the number of gene copies of $m c y A-J$ in the $M$. aeruginosa were the highest among all groups, indicating that the presence of GO at concentration of $0.01 \mathrm{mg} / \mathrm{L}$ stimulated the expression of microcystin synthetase genes clusters (Fig. 4B). This led to a significant increase $(p<0.05)$ in the production of intracellular MCs. Since MCs are synthesized intracellularly and are released to extracellular when the algal cell ruptured (Rincon et al. 2019), the percentage of extracellular MCs release in the $0.01 \mathrm{mg} / \mathrm{LGO}$-exposure group is lower than other groups. However, when the GO-exposure concentration was $10 \mathrm{mg} / \mathrm{L}$, as demonstrated in Fig. 5B, the level of ROS in algal cell increased sharply. The level of ROS in the algal cells increased sharply with increasing GO in the media. The increased ROS and occurrence of cell rupture explain the decreased nutrients removal and significantly increased $(p<0.05)$ extracellular MCs in the $10 \mathrm{mg} / \mathrm{L}$ GO-exposure group. The TEM images in Fig. 5A showed obscure boundaries of the cytomembranes, indicating that severe peroxidation damage and plasmolysis of the algal cells occurred, and a large number of cells were ruptured in the high GO concentration treatments (the red circle in Fig. 2A). Thereupon, lots of intracellular MCs were released, and the percentage of extracellular MCs release was increased significantly $(p<0.05)$.

Furthermore, as shown in Fig. 3A and Fig. 3B, the value of $F_{v} / F_{m}$ and $E T R_{\max }$ of M. aeruginosa cells were the highest among all groups during the GO-exposure was $0.01 \mathrm{mg} / \mathrm{L}$. The $F_{\triangleright} / F_{m}$ value reflects the potential maximum photosynthetic capacity of algal cells (Joonas et al. 2019), and the $E T R_{\max }$ value reflects the maximum transmission rate of photons in photosynthesis of $M$. aeruginosa (Lee et al. 2019). The higher $F_{v} / F_{m}$ and $E T R_{\max }$ values would indicate the better photosynthetic performance (Cruces et al. 2021), and $F_{v} / F_{m}$ value of normal growth of algae is about 0.7-0.8 (Zheng et al. 2020). The highest $F_{\sqrt{v}} / F_{m}$ value is 1.1 in group of GO-exposure at concentration of $0.01 \mathrm{mg} / \mathrm{L}$. Therefore, the photosynthetic performance was stimulated by GO-exposure at concentration of $0.01 \mathrm{mg} / \mathrm{L}$. In contrast, the $F_{v} / F_{m}$ and $E T R_{\max }$ values in GO-exposure at concentration of $10 \mathrm{mg} / \mathrm{L}$ are the lowest among all groups. From another perspective, the higher the $F_{v} / F_{m}$ and $E T R_{\max }$ values would indicate the less stressed conditions in growth environment of $M$. aeruginosa. The lower the $F_{v} / F_{m}$ and $E T R_{\max }$ values would indicate the more stressed conditions in growth environment and the worse photosynthetic performance 
(Sanz-Martín et al. 2019). Photosynthetic performance, the growth rate in M. aeruginosa increased under $0.01 \mathrm{mg} / \mathrm{L}$ GO-exposure and decreased under $10 \mathrm{mg} / \mathrm{L}$ GO-exposure (Fig. 6C). These results suggested that slight GO-exposure enhanced the photosynthetic activity, growth rate, and MCs production of M. aeruginosa at environmentally relevant concentrations. it could reasonably be inferred that the GO pollution at environmentally relevant concentrations would aggravate the ecological hazard of M. aeruginosa (Gao et al. 2019).

\subsection{Analysis of interactions from metabolomic aspects}

The metabolic pattern of M. aeruginosa under GO-exposures of $0.01 \mathrm{mg} / \mathrm{L}$ and $10 \mathrm{mg} / \mathrm{L}$ were compared with the control without GO-exposure. The GO-exposures at concentration of $0.01 \mathrm{mg} / \mathrm{L}$ and $10 \mathrm{mg} / \mathrm{L}$ were close to the low and high contamination levels of GO in aquatic environments, respectively (Zhang et al. 2020a). The metabolic profiling of $M$. aeruginosa in 0.01 and $10 \mathrm{mg} / \mathrm{L}$ GO-exposure groups are distinct (Fig. 7A), indicating that the metabolites in these two groups are significantly different $(p<0.05)$. A total of 64 differential metabolites were screened (Fig. 7B), while the relative abundance of differential metabolites (Fig. 7C) and significantly different metabolic pathways $(p<0.05)$ in the GO-exposed groups were analyzed (Fig. 8).

After $96 \mathrm{~h}$ of exposure to $0.01 \mathrm{mg} / \mathrm{L}$ of GO, 56 metabolites were upregulated while 8 metabolites were down-regulated (Table 1). The identified metabolites were involved in 4 main physiological processes according to significant enriched pathways $(p<0.05)$, including photosynthetic metabolism, glycometabolism, amino acid metabolism, and lipid metabolism. Much more metabolites were up-regulated instead of down-regulated, indicating that most physiological activities in M. aeruginosa were stimulated at the presence of $0.01 \mathrm{mg} / \mathrm{L} \mathrm{GO}$. In contrast, after $96 \mathrm{~h}$ of GO-exposure at concentration of $10 \mathrm{mg} / \mathrm{L}, 47$ metabolites were up-regulated while 17 metabolites were down-regulated. More metabolites were down-regulated as compared with the $0.01 \mathrm{mg} / \mathrm{L} \mathrm{GO}$ treatment, suggesting that the physiological activities were motivated to initiate the defensive mechanism against GO stress in the $10 \mathrm{mg} / \mathrm{L} \mathrm{GO}$ treatment (Zhang et al. 2019). The result of enrichment analysis of KEGG pathway demonstrated that carbon fixation in photosynthetic process, valine, leucine and isoleucine biosynthesis, and galactose metabolism were significantly 
enriched $(p<0.05)$ in $M$. aeruginosa exposed to GO at concentration of $0.01 \mathrm{mg} / \mathrm{L}$.

The metabolic network map reflects the important interactions between the altered metabolic pathways (Fig. 8). Notably, in $0.01 \mathrm{mg} / \mathrm{L} \mathrm{GO}$-exposure group, an increase in amino acid metabolism including increase in L-threonine, L-valine, L-alanine, and L-proline, was observed. These findings are in accordance with previous studies where an increase in amino acid turnover in stimulated algal cells by low concentration of GO was reported (Ouyang et al. 2020). The other important metabolic pathway found to be altered in $M$. aeruginosa in 0.01 GO-exposure group was nucleotide metabolism, including increase of uracil and hypoxanthine. Proliferating algal cells of $M$. aeruginosa stimulated by GO often demand for nucleotides for the synthesis of cellular materials, which is fulfilled by purines and pyrimidines. Increases in nucleotides indicate that they are needed for cell proliferation (Zhang et al. 2020b). Additionally, glycometabolism and fatty acid metabolism were indicated to be alerted in M. aeruginosa at GO-exposure of $0.01 \mathrm{mg} / \mathrm{L}$. Specifically, increased levels of carbohydrates and numerous unsaturated fatty acids including D-glucose, galacturonate, linoleic acid, glutaric, and tetradecanoic acid were observed. The increase of glycometabolism indicates the vigorous growth of algal cell (Zhang et al. 2018), and unsaturated fatty acid will promote the photosynthetic performance of algal cells (Anto et al. 2020).

Moreover, the reticular correlativity between differential metabolites and other results including $\mathrm{TN}, \mathrm{NH}_{3}-\mathrm{N}, \mathrm{PO}_{4}{ }^{3-}-\mathrm{P}, \mathrm{COD}$, mcyA-J gene copies, MCs production, ARGs (sull, sul2, tet $W$, tetM), $F_{v} / F_{m}, E T R_{\max }$, and growth rate were calculated. Highly interconnected metabolites with high degrees play key roles in the interaction of M. aeruginosa and GO. According to the correlativity analysis between metabolites and other pollutants and factors (sull, sul2, tetM, tetW, mcyA-J, MCs production, $\mathrm{NH}_{3}-\mathrm{N}, \mathrm{TN}, \mathrm{PO}_{4}{ }^{3-}-\mathrm{P}, \mathrm{COD}, \mathrm{F}_{\mathrm{v}} / \mathrm{F}_{\mathrm{m}}, \mathrm{ETR}_{\max }$, growth rate, $\mathrm{ROS}$, and $16 \mathrm{~S} \mathrm{rRNA}$ ) as shown in Fig. 9. Moreover, it demonstrated that there were 23 pairs of positive correlations between the intracellular differential metabolites of $M$. aeruginosa and the abundances of sull, sul2, tetM, and tet $W$ with different GO concentrations. The metabolites that related ARGs abundance were mainly amino acids. The metabolites that related $m c y A-J$ expression were mainly amino acids and small molecule acids. There were 40 pairs of positive correlations between these metabolites and $m c y A-J$. Furthermore, there were 28 pairs of positive correlations between the abundance of sull, sul2, tetM, 
tet $W$ and $m c y A-J$ expression. The impacts and interactions were complicated of abundance of ARGs, $m c y A-J$ expression, MCs production, photosynthesis performance of $M$. aeruginosa, intracellular ROS levels, ultrastructure, and GO. Simultaneously, there is also a close correlation among various different metabolites in M aeruginosa (Kim et al. 2020).

Some chemical substances such as antibiotic contaminants and organic pollutant have been manifest to have toxic stimulant hormesis effects on algae at a certain concentration (Liu et al. 2020). Nanomaterials are also reported to have a hormesis effect on many kinds of algal cells (Agathokleous et al. 2019). The phenomenon of hormesis effect was observed in the $M$. aeruginosa in GO-exposure in the present study. Photosynthesis is the basis of a cell growth of $M$. aeruginosa, photosynthetic performance was promoted by GO-exposure at $0.01 \mathrm{mg} / \mathrm{L}$ (Wang et al. 2020b). The GO stimulated the growth rate, and then promoted the production of MCs in $M$. aeruginosa (Yu et al. 2019).

Particularly, the gene copies of microcystin synthetase (mcyA-J) increased. It was reasonable to conclude that the increased genetic expression of microcystin synthetase had resulted in the increased production of MCs. In contrast, the expression of $m c y A-J$ was inhibited in the $10 \mathrm{mg} / \mathrm{L}$ GO- exposed group, and consequently, MCs production decreased. The results suggested that the MCs synthetic process is stimulated by low and inhibited by high concentration of GO.

The ARGs and mcyA-J were significantly related with photosynthetic metabolites including phytol (an essential component of chlorophyll) and 3-6-anhydro-D-glucose (photosynthetic carbon fixes important metabolites) (Zhang et al. 2018). Moreover, some studies have demonstrated that microcystin synthetase genes $(m c y A-J)$ and MCs production was a kind of physiological response to environmental stressed factors ( $\mathrm{Li}$ et al. 2019). These results confirmed that the role of MCs production and synthesis in responsive process to GO-exposure at environmental concentration ( $\underline{\mathrm{Li}}$ et al. 2019).

The M. aeruginosa released more MCs in the $10 \mathrm{mg} / \mathrm{L}$ GO-exposure group than in the control and the $0.01 \mathrm{mg} / \mathrm{L} \mathrm{GO}$ treatment. The increased ROS level and membranolysis (Fig. 5) may facilitate the export of intracellular MCs ( $\mathrm{Li}$ et al. 2019). The cells rupturing induced by GO-exposure might be an important explanation for the MCs release by M. aeruginosa ( $\underline{\mathrm{Li} \text { et al. }}$ 
2020). With increased intracellular MCs production and sull, sul2, tetM, tetW abundance at low concentration of GO and increased release of MCs at high concentration of GO, the hazards of $M$. aeruginosa and ARGs would be exacerbated by GO in the aquatic environment (Bandara et al.

348 2019). It suggested that the harm of GO by regulating the ARGs abundance, microcystin synthetase genes, and MCs production has already become an ecological problem.

During the GO-exposure period of $96 \mathrm{~h}$, impacts and interactions of ARGs, microcystin synthetase genes, MCs production, photosynthesis were initiated. The relative abundance of carbohydrates related to the carbon fixation pathway in photosynthetic process in $M$. aeruginosa increased significantly $(p<0.05)$ in GO-exposure at concentration of $0.01 \mathrm{mg} / \mathrm{L}$. Simultaneously, the expression of mcyA-J in $M$. aeruginosa and sul1, sul2, tetM, tet $W$ in synthetic wastewater increased significantly $(p<0.05)$, resulting in the increase of intracellular MCs production and ARGs spread. The microcystin synthetase gene cluster of mcyA-J can regulate the ABC transporters (control the transportation and exchange of nutrients between extracellular and intracellular) (Han et al. 2019, Pearson et al. 2020). The result of KEGG pathway enrichment analysis suggested that the pathway of $\mathrm{ABC}$ transporters was significantly enriched, and the metabolites (valine, maltotriose, D-glucose, D-maltose, threonine, alanine, proline) which matched in the transporter pathway were up-regulated. It means that more extracellular nutrients (such as $\mathrm{NH}_{3}-\mathrm{N}$ ) and ARGs plasmid of sull, sul2, tetM, tetW in synthetic wastewater will be transported into M. aeruginosa for cell growth, MCs synthesis and spread of ARGs (Yu et al. 2019). When the concentration of GO-exposure increased to $10 \mathrm{mg} / \mathrm{L}$, cytoderm rupture occurred and large amounts of intracellular MCs was released. It indicated that hormesis mechanism would be triggered in M. aeruginosa and ARGs abundance when the GO presents. The presence of $\mathrm{GO}$ at finite concentration in aquatic environment can aggravate the harm of M. aeruginosa and spread of ARGs (Duan et al. 2020, Huang et al. 2020).

\section{Conclusions}


graphene oxide, and M. aeruginosa in synthetic wastewater were investigated in the present study. There was significant correlation between the abundance of ARGs (sull, sul2, tetM, tetW) and $m c y A-J$ expression when the GO concentration was $0.01 \mathrm{mg} / \mathrm{L}$. GO has a hormesis effect on $M$. aeruginosa, ARGs abundance, and mcyA-J expression. At low concentration of $0.01 \mathrm{mg} / \mathrm{L}, \mathrm{GO}$ would stimulate the photosynthesis and growth of M. aeruginosa, while at high concentration of $10 \mathrm{mg} / \mathrm{L}, \mathrm{GO}$ would induce cell rupture and MCs release of M. aeruginosa. The GO in aquatic environment would aggravate the ecological hazard of M. aeruginosa by promoting its growth, mcyA-J expression, MCs production, and ARGs abundance.

\section{Acknowledgments}

This work was financially sponsored by Shanghai Sailing Program (20YF1447700) and National Natural Science Foundation of China (32001201).

\section{Funding Information}

(1) Shanghai Sailing Program

Award Number: 20YF1447700 | Recipient: Xiyan Ji

(2) National Natural Science Foundation of China

Award Number: 32001201 | Recipient: Xiyan Ji

\section{Ethical Approval}

This research does not involve ethical issues.

\section{Consent to Participate}

This research does not involve ethical issues. 
All authors confirm that this paper has not been published before in any form.

\section{Authors Contributions}

394 Xiyan Ji: Conceptualization, Methodology, Supervision, Funding acquisition

395 Meifang Hou: Supervision, Conceptualization, Review \& Editing

396 Shichao Wu: Validation, Formal analysis, Investigation, Data Curation, Writing - Original Draft

397 Xin Li: Resources, Data Curation, Formal analysis

398 Jing Ye: Review \& Editing

399 Wenwu Xu: Project administration

400 Rui Wang: Visualization

\section{Competing Interests}

402

403

404

The authors declare that they have no known competing financial interests or personal relationships that could have appeared to influence the work reported in this paper.

\section{Availability of data and materials}

The datasets used or analyzed during the current study are available from the corresponding author on reasonable request.

\section{References}

Agathokleous E, Feng Z, Iavicoli I, Calabrese EJJEi (2019): The two faces of nanomaterials: A quantification of hormesis in algae and plants. 131,105044

Ajayan K, Harilal C, Gani PJAR (2019): Performance of reflector coated LED Bio-box on the 

augmentation of growth and lipid production in aerophytic trebouxiophyceaen algae Coccomyxa sp. $\quad 38,101401$

Anto S, Mukherjee SS, Muthappa R, Mathimani T, Deviram G, Kumar SS, Verma TN, Pugazhendhi AJC (2020): Algae as green energy reserve: Technological outlook on biofuel production. 242, 125079

Aphale A, Chattopadhyay A, Mahakalakar K, Patra PJJon, nanotechnology (2015): Synthesis and electrochemical analysis of algae cellulose-polypyrrole-graphene nanocomposite for supercapacitor electrode. $15,6225-6229$

Avant B, Bouchard D, Chang X, Hsieh H-S, Acrey B, Han Y, Spear J, Zepp R, Knightes CDJN (2019): Environmental fate of multiwalled carbon nanotubes and graphene oxide across different aquatic ecosystems. $\quad 13,1-12$

Bandara PC, Perez JVD, Nadres ET, Nannapaneni RG, Krakowiak KJ, Rodrigues DFJAAPM (2019): Graphene oxide nanocomposite hydrogel beads for removal of selenium in contaminated water. $1,2668-2679$

Chen L, Chen J, Zhang X, Xie PJJohm (2016): A review of reproductive toxicity of microcystins. 301, 381-399

Conley DJ, Paerl HW, Howarth RW, Boesch DF, Seitzinger SP, Karl E KE, Lancelot C, Gene E GEJS (2009): Controlling eutrophication: nitrogen and phosphorus. 123, 1014-1015

Cruces E, Barrios AC, Cahue YP, Januszewski B, Gilbertson LM, Perreault FJC (2021): Similar toxicity mechanisms between graphene oxide and oxidized multi-walled carbon nanotubes in Microcystis aeruginosa. 265, 129137

Duan Y, Guo X, Yang J, Zhang M, Li YJRSos (2020): Nutrients recycle and the growth of Scenedesmus obliquus in synthetic wastewater under different sodium carbonate concentrations. 7, 191214

Elser JJ, Bracken ME, Cleland EE, Gruner DS, Harpole WS, Hillebrand H, Ngai JT, Seabloom EW, Shurin JB, Smith JEJEl (2007): Global analysis of nitrogen and phosphorus limitation of primary producers in freshwater, marine and terrestrial ecosystems. 10, 1135-1142

Fan G, Ning R, Yan Z, Luo J, Du B, Zhan J, Liu L, Zhang JJJoHM (2021): Double photoelectron-transfer mechanism in $\mathrm{Ag}-\mathrm{AgCl} / \mathrm{WO} / \mathrm{g}-\mathrm{C} 3 \mathrm{~N} 4$ photocatalyst with enhanced visible-light photocatalytic activity for trimethoprim degradation. 403,123964

Gao M, Yang Y, Song ZJE, safety e (2019): Effects of graphene oxide on cadmium uptake and 
photosynthesis performance in wheat seedlings. $173,165-173$

Grasso G, Zane D, Dragone RJN (2020): Microbial nanotechnology: Challenges and prospects for green biocatalytic synthesis of nanoscale materials for sensoristic and biomedical applications. 10 , 11

Guo J, Ma Z, Peng J, Mo J, Li Q, Guo J, Yang FJJoHM (2021): Transcriptomic analysis of Raphidocelis subcapitata exposed to erythromycin: The role of DNA replication in hormesis and growth inhibition. 402,123512

Han T, Liang Y, Wu Z, Zhang L, Liu Z, Li Q, Chen X, Guo W, Jiang L, Pan FJJohm (2019): Effects of tetracycline on growth, oxidative stress response, and metabolite pattern of ryegrass. 380, 120885

Huang F, Pan L, He Z, Zhang M, Zhang MJSoTTE (2020): Identification, interactions, nitrogen removal pathways and performances of culturable heterotrophic nitrification-aerobic denitrification bacteria from mariculture water by using cell culture and metagenomics. 732,139268

Jiang Y, Liu Y, Zhang JJEP (2020): Antibiotic contaminants reduced the treatment efficiency of UV-C on Microcystis aeruginosa through hormesis. 261, 114193

Jiang Y, Liu Y, Zhang JJJoHM (2021): Mechanisms for the stimulatory effects of a five-component mixture of antibiotics in Microcystis aeruginosa at transcriptomic and proteomic levels. 406, 124722

Joonas E, Aruoja V, Olli K, Kahru AJSotte (2019): Environmental safety data on CuO and TiO2 nanoparticles for multiple algal species in natural water: filling the data gaps for risk assessment. $647,973-980$

Kim M, Lee J, Yang D, Park HY, Park WJEP (2020): Seasonal dynamics of the bacterial communities associated with cyanobacterial blooms in the Han River. 266, 115198

Komijani M, Shamabadi NS, Shahin K, Eghbalpour F, Tahsili MR, Bahram MJEP (2021): Heavy metal pollution promotes antibiotic resistance potential in the aquatic environment. 274,116569

Lee H, Brown MT, Choi S, Pandey LK, De Saeger J, Shin K, Kim JK, Depuydt S, Han T, Park JJJohm (2019): Reappraisal of the toxicity test method using the green alga Ulva pertusa Kjellman (Chlorophyta). 369, 763-769

Lee J, Choi J, Fatka M, Swanner E, Ikuma K, Liang X, Leung T, Howe AJWr (2020): Improved detection of mcyA genes and their phylogenetic origins in harmful algal blooms. 176,115730 
Li S, Tao Y, Zhan X-M, Dao G-H, Hu H-YJSoTTE (2020): UV-C irradiation for harmful algal blooms control: A literature review on effectiveness, mechanisms, influencing factors and facilities. 723,137986

Li X, Li J, Meng F, Yao LJE, safety e (2019): Hepatotoxicity and immunotoxicity of MC-LR on silver carp. $169,28-32$

Liu X, Yan B, Li Y, Ma X, Jiao W, Shi K, Zhang T, Chen S, He Y, Liang X-JJAn (2020): Graphene oxide-grafted magnetic nanorings mediated magnetothermodynamic therapy favoring reactive oxygen species-related immune response for enhanced antitumor efficacy. 14, 1936-1950

Lu J, Struewing I, Wymer L, Tettenhorst DR, Shoemaker J, Allen JJWr (2020a): Use of qPCR and RT-qPCR for monitoring variations of microcystin producers and as an early warning system to predict toxin production in an Ohio inland lake. 170, 115262

Lu N, Ling L, Guan T, Wang L, Wang D, Zhou J, Ruan T, Shen X, Li X, Sun YJT (2020b): Broad-specificity ELISA with a heterogeneous strategy for sensitive detection of microcystins and nodularin. $\quad 175,44-48$

Ma X, Zhou W, Fu Z, Cheng Y, Min M, Liu Y, Zhang Y, Chen P, Ruan RJBt (2014): Effect of wastewater-borne bacteria on algal growth and nutrients removal in wastewater-based algae cultivation system. $167,8-13$

McLellan NL, Manderville RAJTr (2017): Toxic mechanisms of microcystins in mammals. 6, 391-405

Monteil C, Bar N, Moreau B, Retoux R, Bee A, Talbot D, Villemin DJP, Characterization PS (2014): Phosphonated Polyethylenimine-Coated Nanoparticles: Size-and Zeta-Potential-Adjustable Nanomaterials. $\quad 31,219-227$

Ouyang S, Zhou Q, Zeng H, Wang Y, Hu XJEs, technology (2020): Natural Nanocolloids Mediate the Phytotoxicity of Graphene Oxide. 54, 4865-4875

Pan S-D, Chen X-H, Li X-P, Cai M-Q, Shen H-Y, Zhao Y-G, Jin M-CJJoMCA (2015): In situ controllable synthesis of graphene oxide-based ternary magnetic molecularly imprinted polymer hybrid for efficient enrichment and detection of eight microcystins. 3, 23042-23052

Pearson LA, Crosbie ND, Neilan BAJM, Research F (2020): Distribution and conservation of known secondary metabolite biosynthesis gene clusters in the genomes of geographically diverse Microcystis aeruginosa strains. $71,701-716$

Pinheiro C, Azevedo J, Campos A, Vasconcelos V, Loureiro SJE (2016): The interactive effects of 
microcystin-LR and cylindrospermopsin on the growth rate of the freshwater algae Chlorella vulgaris. $25,745-758$

Poudyal D, Rosenqvist E, Ottosen C-OJFpb (2019): Phenotyping from lab to field-tomato lines screened for heat stress using Fv/Fm maintain high fruit yield during thermal stress in the field. 46, 44-55

Rincon SM, Urrego NF, Avila KJ, Romero HM, Beyenal HJAR (2019): Photosynthetic activity assessment in mixotrophically cultured Chlorella vulgaris biofilms at various developmental stages. $\quad 38,101408$

Rzymski P, Klimaszyk P, Jurczak T, Poniedziałek BJFiM (2020): Oxidative stress, programmed cell death and microcystin release in Microcystis aeruginosa in response to Daphnia grazers. 11

Sanz-Martín M, Hendriks IE, Carstensen J, Marbà N, Krause-Jensen D, Sejr MK, Duarte CMJAB (2019): Continuous photoperiod of the Artic summer stimulates the photosynthetic response of some marine macrophytes. 158,103126

Soares C, Pereira R, Martins M, Tamagnini P, Serôdio J, Moutinho-Pereira J, Cunha A, Fidalgo FJJoHM (2020): Glyphosate-dependent effects on photosynthesis of Solanum lycopersicum L._An ecophysiological, ultrastructural and molecular approach. 398, 122871

Sola AJN (2020): Abuse of antibiotics in perinatology: negative impact for health and the economy. 21, e559-e570

Sun J, Bu L, Deng L, Shi Z, Zhou SJCEJ (2018): Removal of Microcystis aeruginosa by UV/chlorine process: Inactivation mechanism and microcystins degradation. 349, 408-415

Sun W, Qian X, Gu J, Wang X-J, Zhang L, Guo A-YJBt (2017): Mechanisms and effects of arsanilic acid on antibiotic resistance genes and microbial communities during pig manure digestion. 234, $217-223$

Sun Y, Cao N, Duan C, Wang Q, Ding C, Wang JJJoHM (2021): Selection of antibiotic resistance genes on biodegradable and non-biodegradable microplastics. 409, 124979

Wang C, Yang Y, Hou J, Wang P, Miao L, Wang X, Guo LJAR (2020a): Optimization of cyanobacterial harvesting and extracellular organic matter removal utilizing magnetic nanoparticles and response surface methodology: A comparative study. 45, 101756

Wang H, Jin M, Mao W, Chen C, Fu L, Li Z, Du S, Liu HJSoTTE (2020b): Photosynthetic toxicity of non-steroidal anti-inflammatory drugs (NSAIDs) on green algae Scenedesmus obliquus. 707, 
Weckwerth W, Wenzel K, Fiehn OJP (2004): Process for the integrated extraction, identification and quantification of metabolites, proteins and RNA to reveal their co-regulation in biochemical networks. $4,78-83$

Wei J, Xie X, Huang F, Xiang L, Wang Y, Han T, Massey IY, Liang G, Pu Y, Yang FJEp (2020): Simultaneous Microcystis algicidal and microcystin synthesis inhibition by a red pigment prodigiosin. 256,113444

Wu D-L, Zhang M, He L-X, Zou H-Y, Liu Y-S, Li B-B, Yang Y-Y, Liu C, He L-Y, Ying G-GJSoTTE (2020a): Contamination profile of antibiotic resistance genes in ground water in comparison with surface water. 715,136975

Wu X, Wu H, Gu X, Zhang R, Sheng Q, Ye JJEP (2020b): Effect of the immobilized microcystin-LR-degrading enzyme MlrA on nodularin degradation and its immunotoxicity study. 258,113653

Xu S, Liu Y, Zhang J, Gao BJC (2021): Proteomic mechanisms for the combined stimulatory effects of glyphosate and antibiotic contaminants on Microcystis aeruginosa. 267, 129244

Yang Z, Kong F, Shi X, Yu Y, Zhang MJJoHM (2015): Effects of UV-B radiation on microcystin production of a toxic strain of Microcystis aeruginosa and its competitiveness against a non-toxic strain. $283,447-453$

Yang Z, Hao X, Chen S, Ma Z, Wang W, Wang C, Yue L, Sun H, Shao Q, Murugadoss VJJoc, science i (2019): Long-term antibacterial stable reduced graphene oxide nanocomposites loaded with cuprous oxide nanoparticles. 533, 13-23

Yin J, Fan W, Du J, Feng W, Dong Z, Liu Y, Zhou TJEP (2020): The toxicity of graphene oxide affected by algal physiological characteristics: A comparative study in cyanobacterial, green algae, diatom. 260, 113847

Yu S, Li C, Xu C, Effiong K, Xiao XJE, safety e (2019): Understanding the inhibitory mechanism of antialgal allelochemical flavonoids from genetic variations: photosynthesis, toxin synthesis and nutrient utility. $177,18-24$

Zhang H, Meng G, Mao F, Li W, He Y, Gin KY-H, Ong CNJJohm (2019): Use of an integrated metabolomics platform for mechanistic investigations of three commonly used algaecides on cyanobacterium, Microcystis aeruginosa. $\quad 367,120-127$ 
Zhang M, Wang X, Tao J, Li S, Hao S, Zhu X, Hong YJE, safety e (2018): PAHs would alter cyanobacterial blooms by affecting the microcystin production and physiological characteristics of Microcystis aeruginosa. 157, 134-142

Zhang Q, Hou Q, Huang G, Fan QJES, Research P (2020a): Removal of heavy metals in aquatic environment by graphene oxide composites: a review. 27, 190-209

Zhang X, Hu C, Sun X, Zang X, Zhang X, Fang T, Xu NJA (2020b): Comparative transcriptome analysis reveals chitooligosaccharides-induced stress tolerance of Gracilariopsis lemaneiformis under high temperature stress. 519,734876

Zhao P, Liu S, Huang W, He L, Li J, Zhou J, Zhou JJC (2020a): Influence of eugenol on algal growth, cell physiology of cyanobacteria Microcystis aeruginosa and its interaction with signaling molecules. 255, 126935

Zhao Y, Liu Y, Zhang X, Liao WJC (2020b): Environmental transformation of graphene oxide in the aquatic environment. 127885

Zheng L, Steppe K, Van Labeke MCJPp (2020): Spectral quality of monochromatic LED affects photosynthetic acclimation to high-intensity sunlight of Chrysanthemum and Spathiphyllum. $169,10-26$

Zhu G, Cui X, Zhang Y, Chen S, Dong M, Liu H, Shao Q, Ding T, Wu S, Guo ZJP (2019): Poly (vinyl butyral)/graphene oxide/poly (methylhydrosiloxane) nanocomposite coating for improved aluminum alloy anticorrosion. 172, 415-422 
Figures

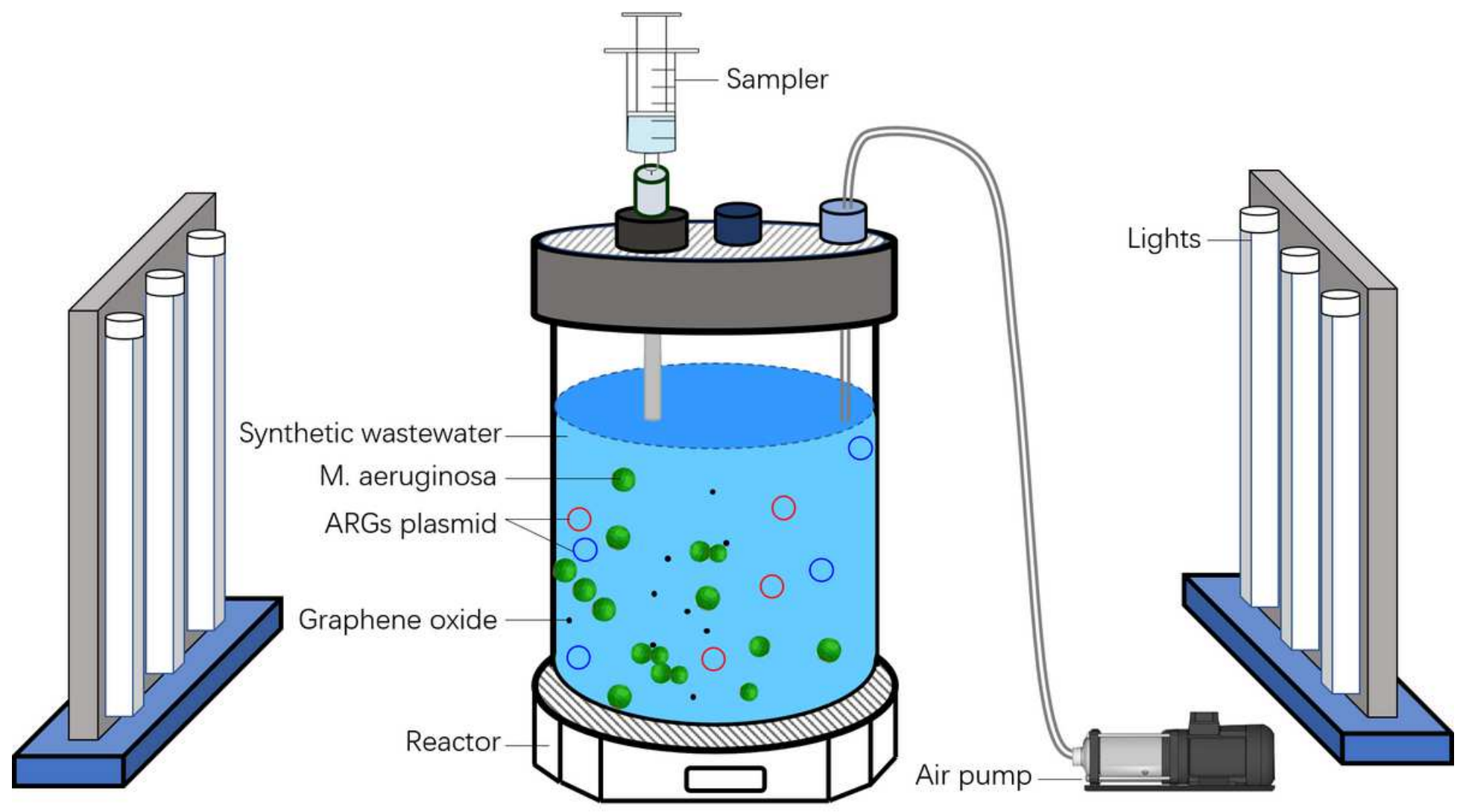

Figure 1

Schematic diagram of experimental set-up 
$24 \mathrm{~h}$

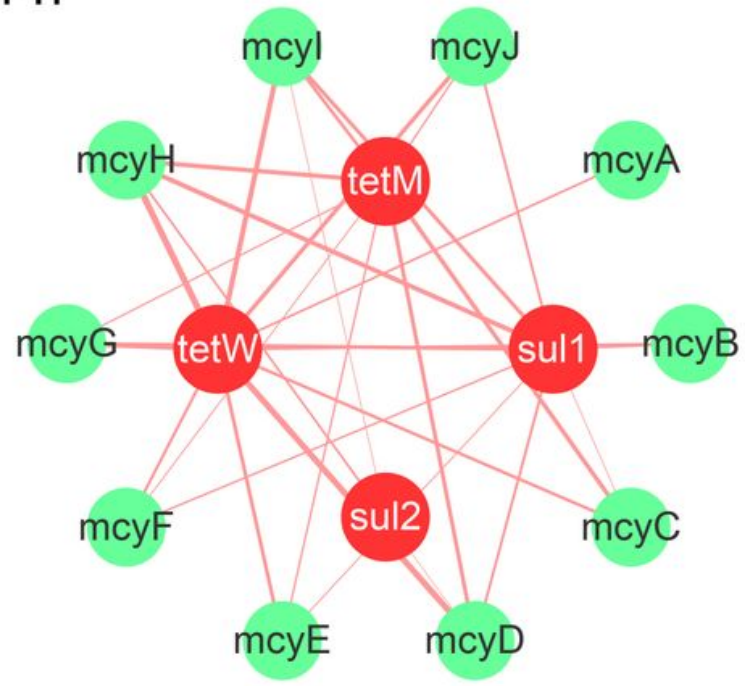

$72 \mathrm{~h}$

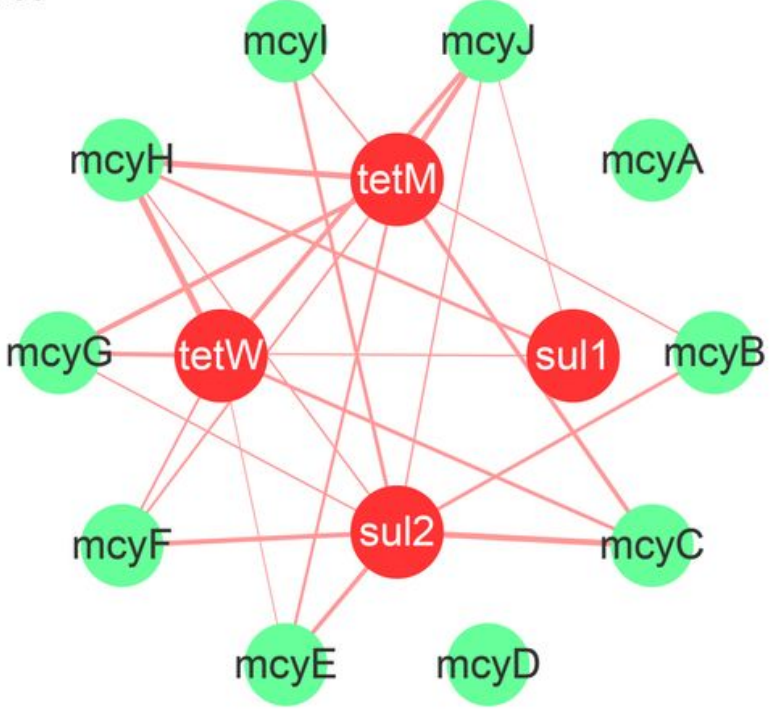

$48 \mathrm{~h}$

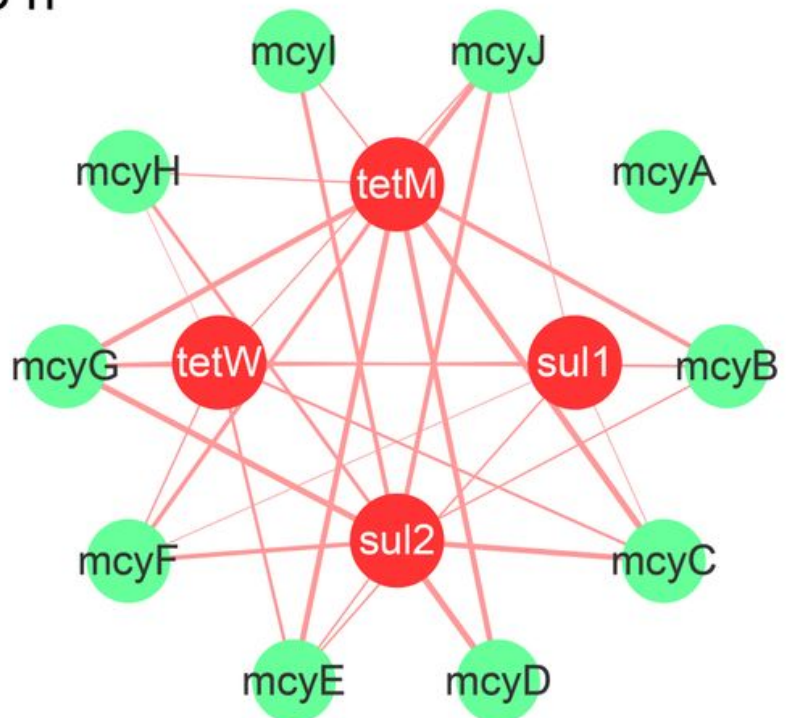

$96 \mathrm{~h}$

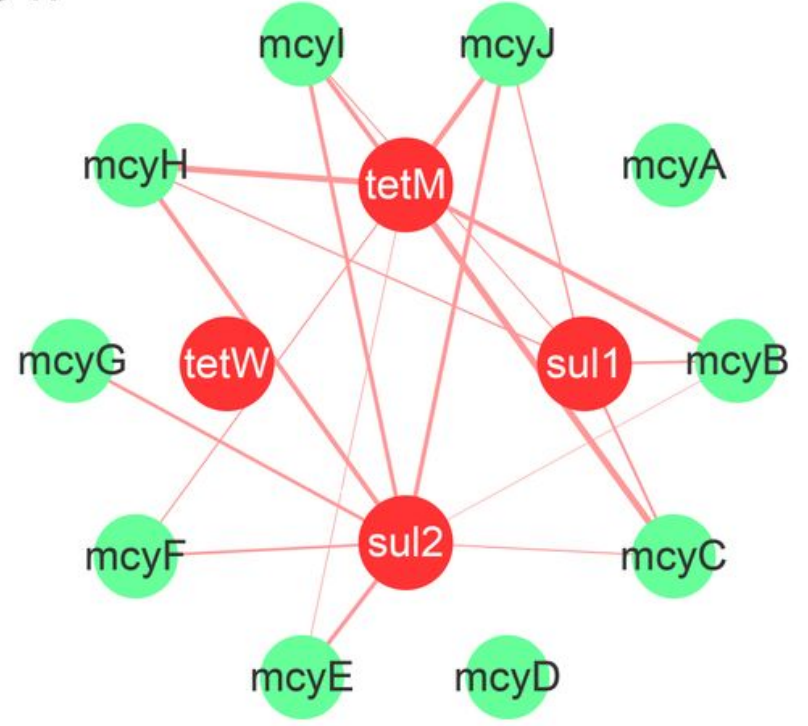

Figure 2

Pearson correlation analysis between abudances of sul1, sul2, tetM, tetW and mcyA-J expressions 

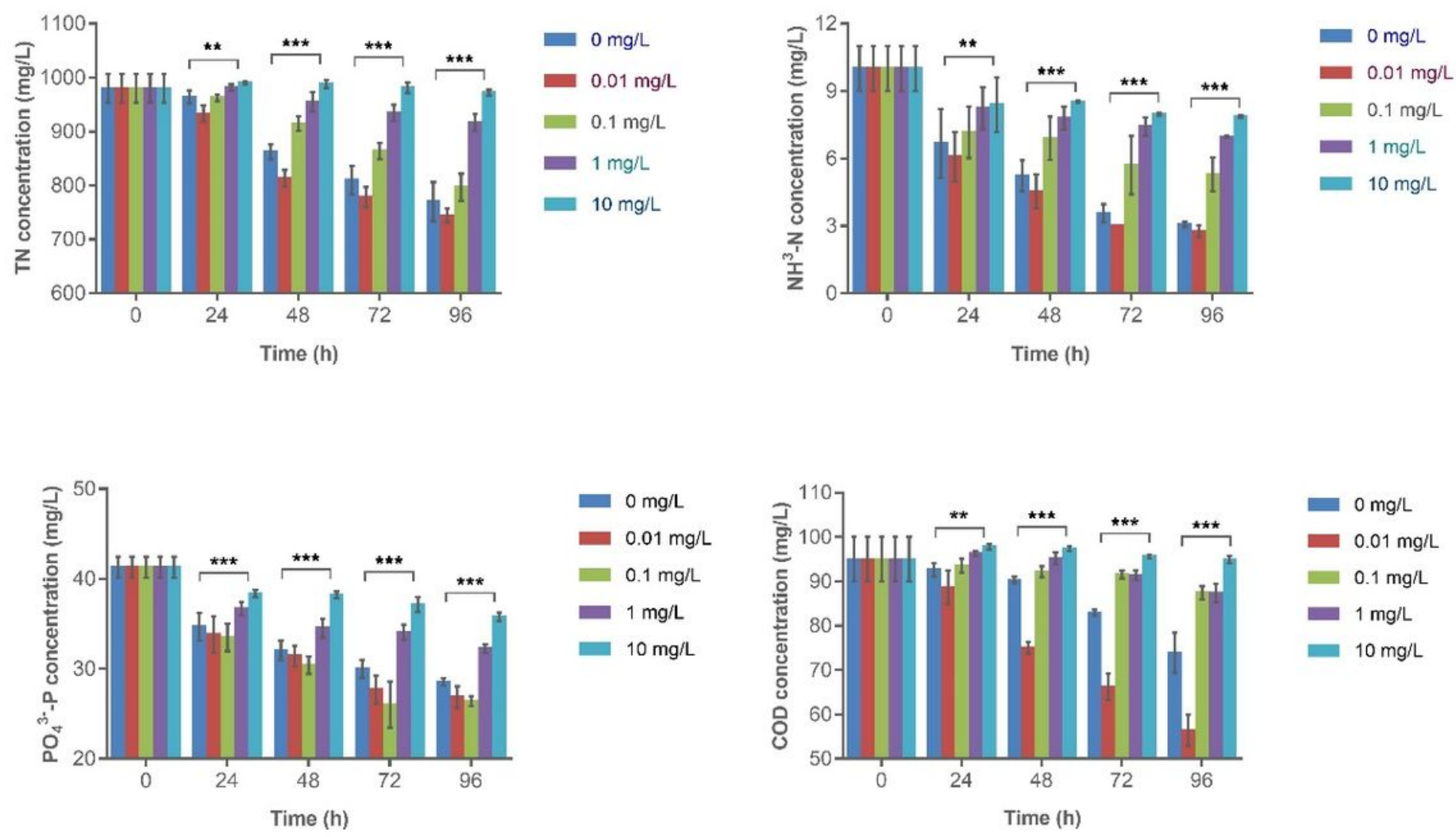

Figure 3

Changes in TN, NH3-N, P043-P, and COD concentrations during the 96-h incubation of M. aeruginosa in BG11 medium with $0,0.01,0.1,1$, and $10 \mathrm{mg} / \mathrm{L}$ graphene oxide (GO) 
A

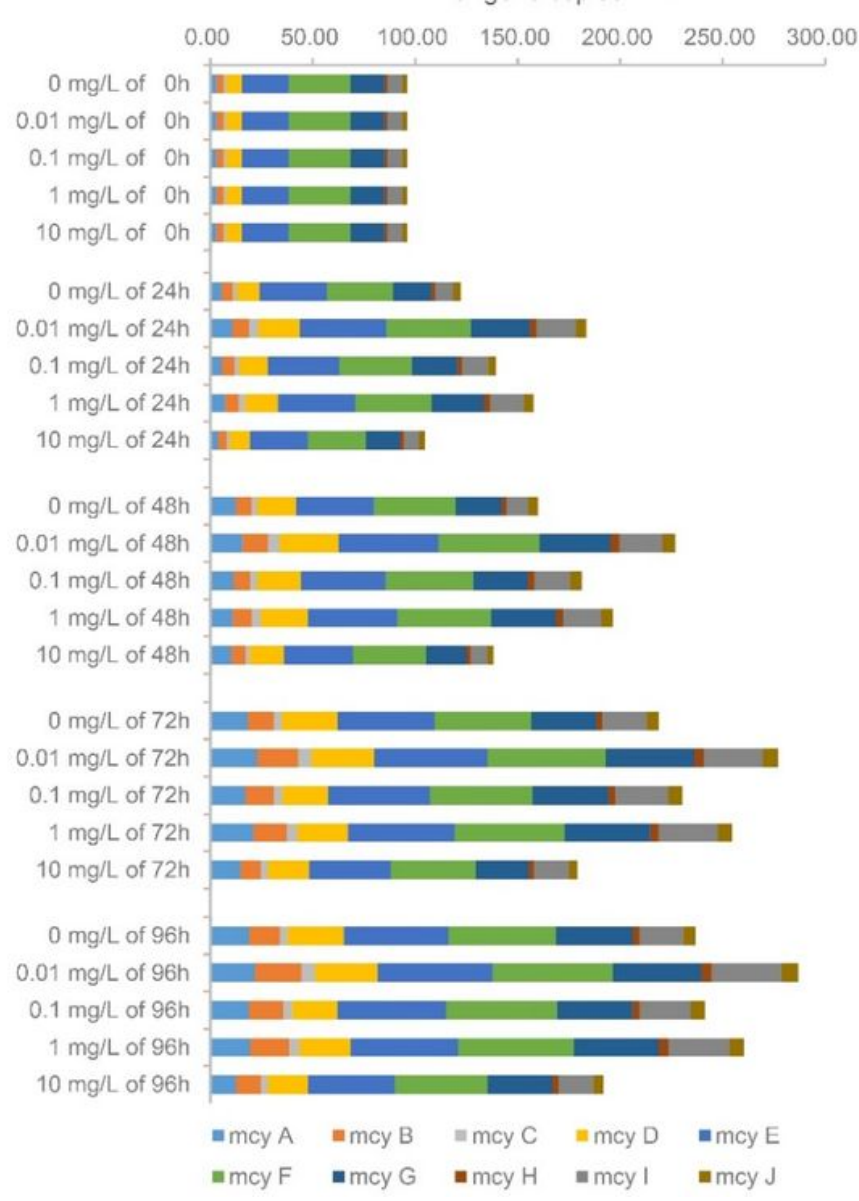

B

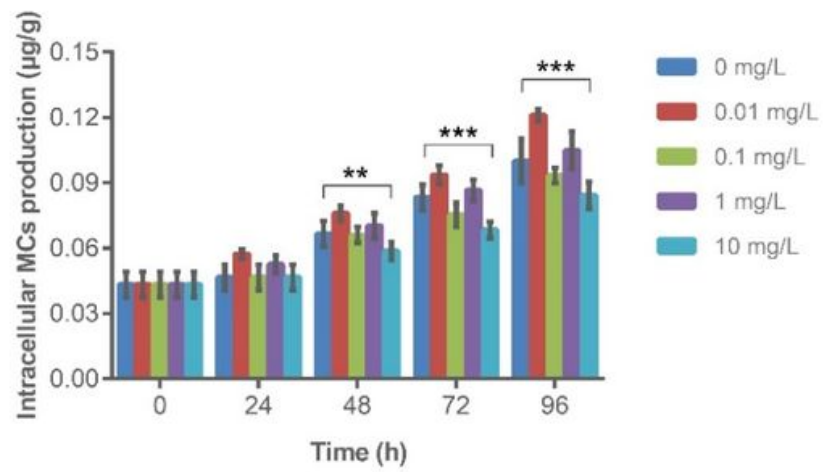

C

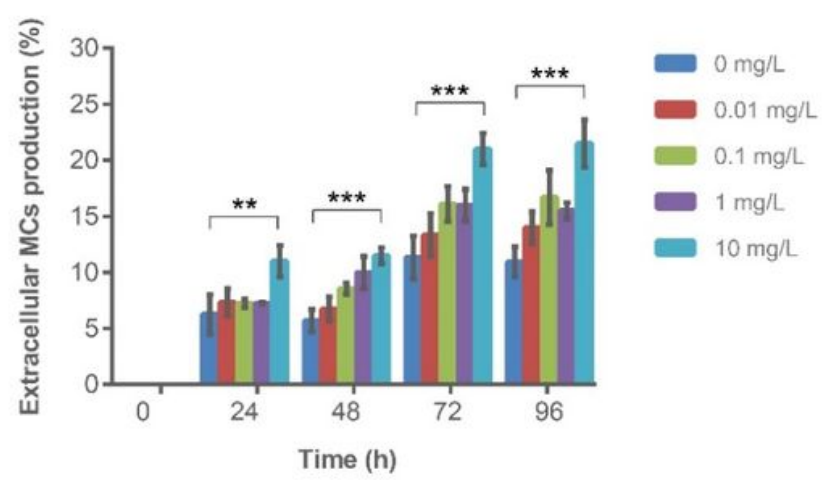

\section{Figure 4}

A: The expression of microcystis synthase gene cluster (mcy A-J) in M. aeruginosa in 0.01, 0.1, 1, 10 mg/L GO-exposure groups and control group; B: The intracellular MCs production in M. aeruginosa in 0.01, 0.1, 1, 10 mg/L GO-exposure groups and control group; C: The percentage of extracellular MCs production in $\mathrm{M}$. aeruginosa in $0.01,0.1,1,10 \mathrm{mg} / \mathrm{L} \mathrm{GO}$-exposure groups and control group. 

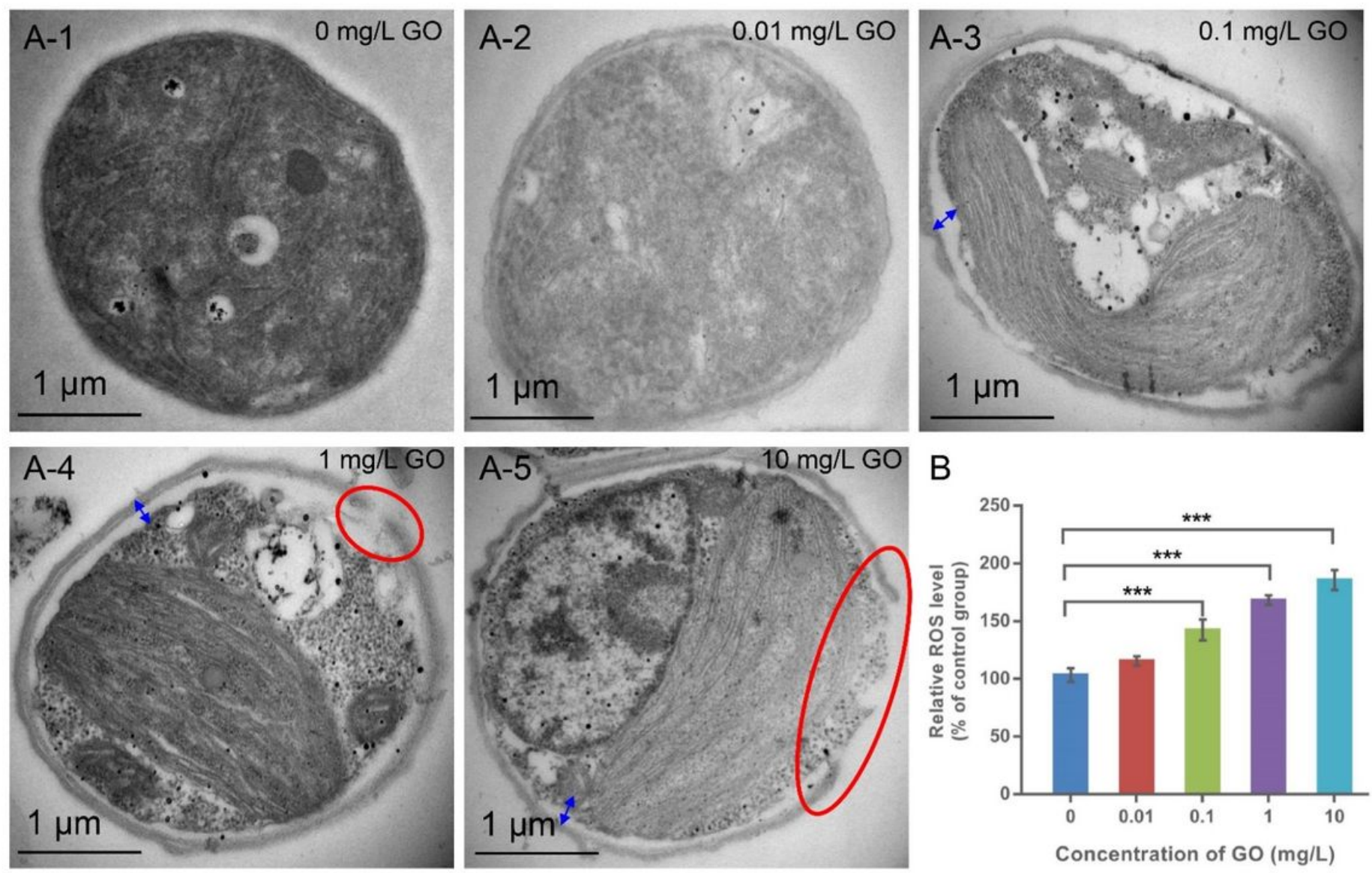

\section{Figure 5}

The TEM images and ROS levels of $\mathrm{M}$. aeruginosa in $0.01,0.1,1,10 \mathrm{mg} / \mathrm{L}$ GO-exposure groups and control group. A1-A5: ultrastructure of the M. aeruginosa. double-headed arrows denote plasmolysis of M. aeruginosa, red circles denote breakages of M. aeruginosa. B: ROS levels of M. aeruginosa in all groups.

A

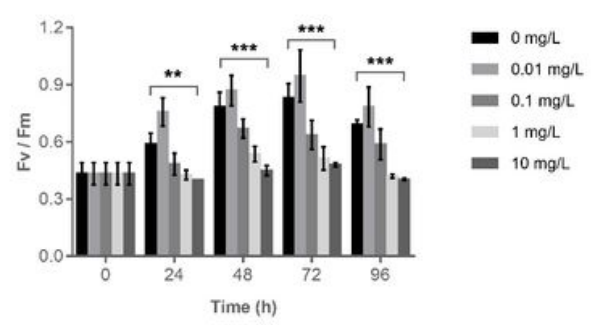

B

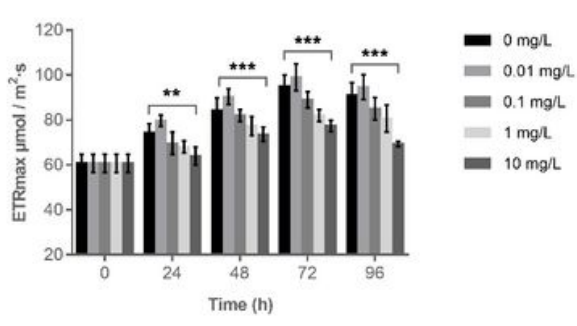

C

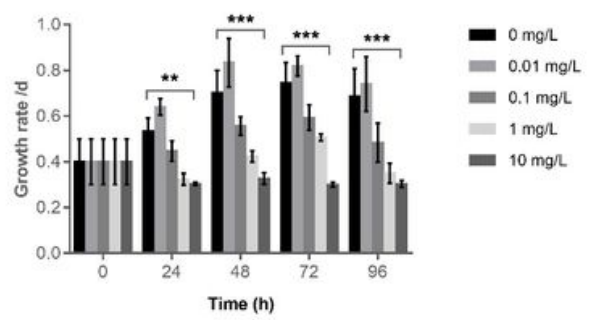

\section{Figure 6}

The Fv/Fm, ETRmax, and growth rate of M. aeruginosa in 0, 0.01, 0.1, 1, $10 \mathrm{mg} / \mathrm{L}$ GO-exposure groups and control group. A: Fv/Fm of the M. aeruginosa in all groups, B: ETRmax of the M. aeruginosa in all groups, $\mathrm{C}$ : growth rate of the $\mathrm{M}$. aeruginosa in all groups. 
A

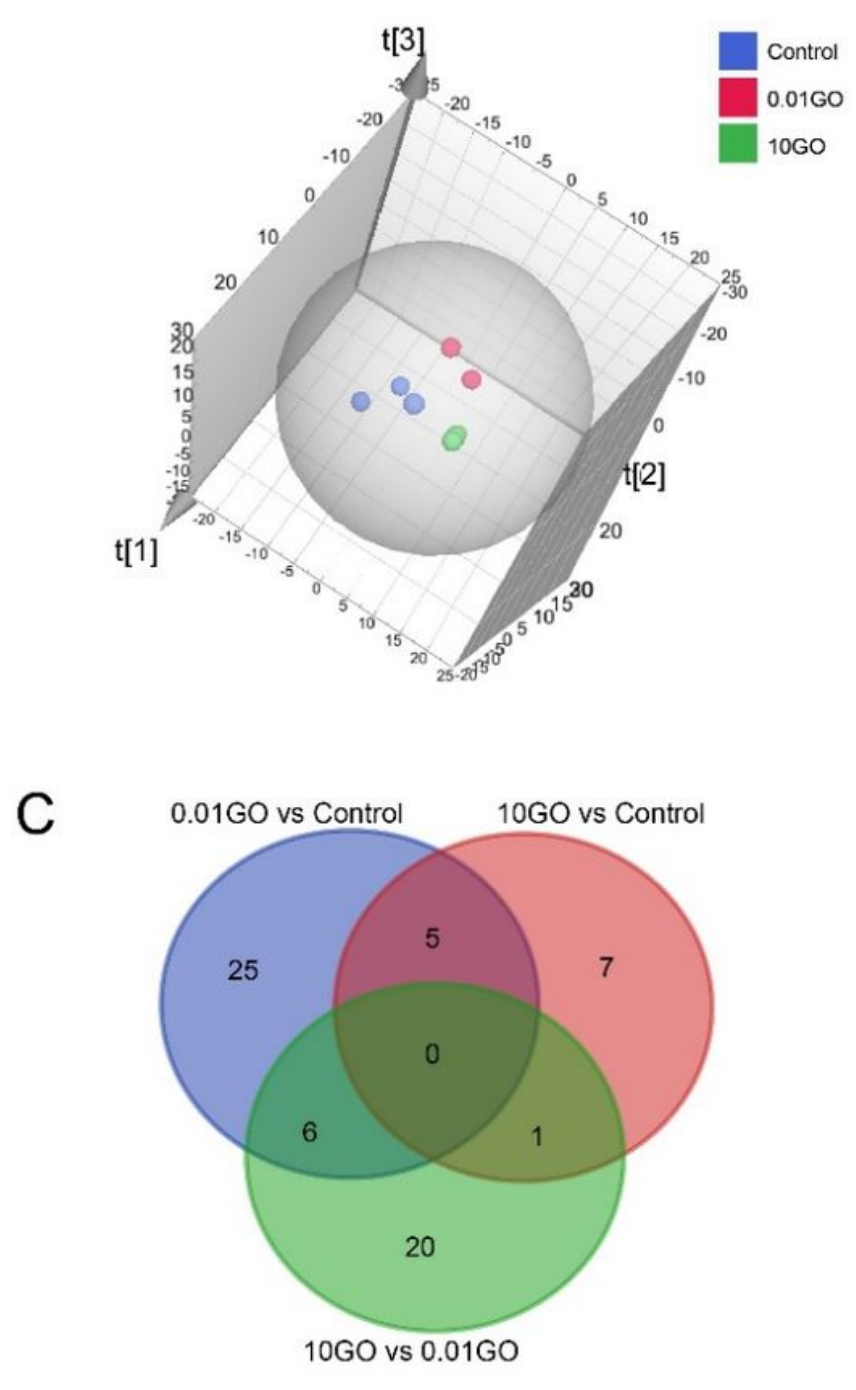

B

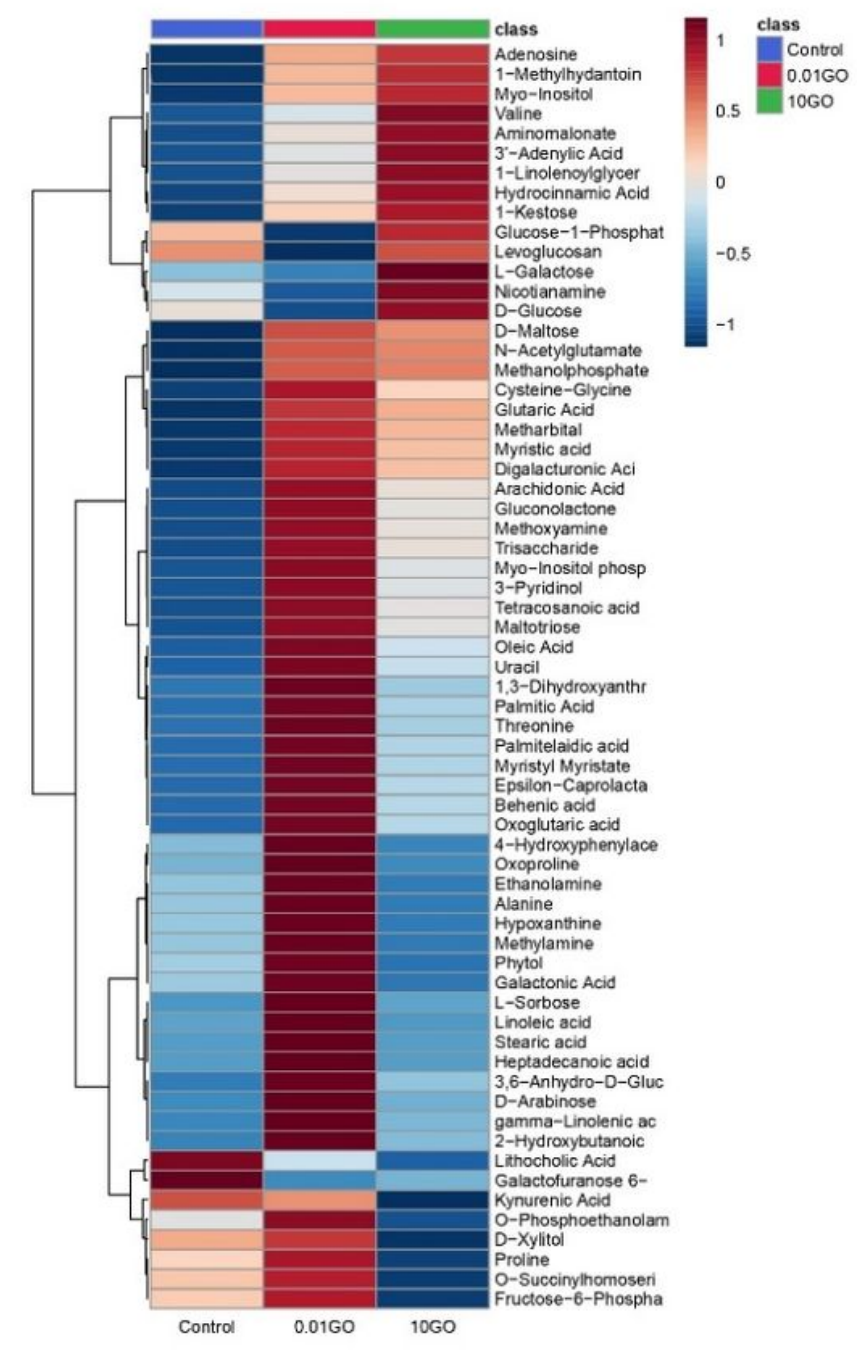

Figure 7

The metabolic analysis of M. aeruginosa in different concentration of GO-exposure. A: PCA analysis, B: metabolite heat map of control group, $0.01 \mathrm{mg} / \mathrm{L}$ GO-exposure, $10 \mathrm{mg} / \mathrm{L}$ GO-exposure. C: venn diagram of the differential metabolites. 


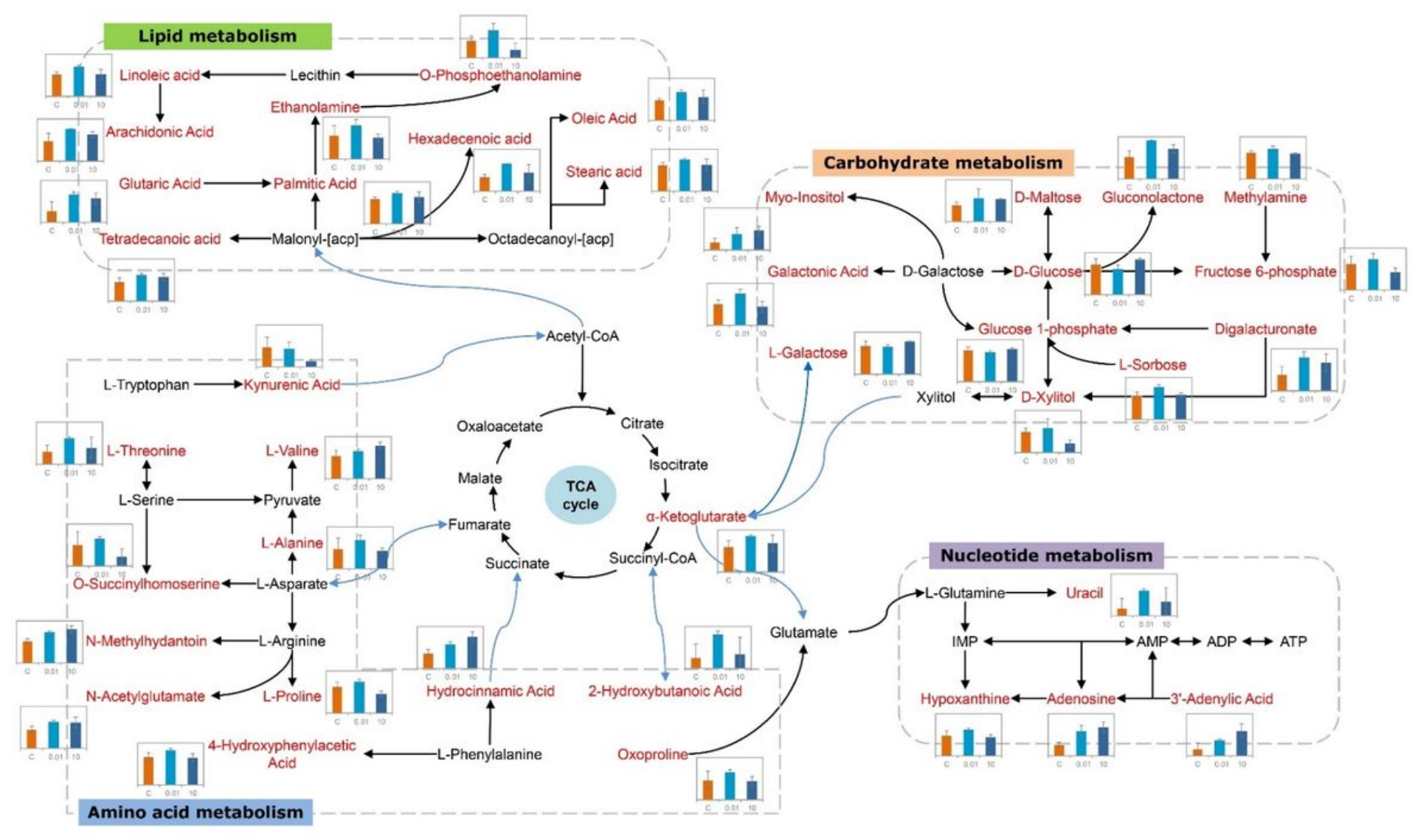

Figure 8

Metabolic pathway network map of significant altered metabolites of $0.01 \mathrm{mg} / \mathrm{L}, 10 \mathrm{mg} / \mathrm{L}$ GO-exposure, and control group. Metabolites identified in this study are shown along with a bar plot illustrating normalized concentration differences of metabolites in control group (saffron yellow bar), $0.01 \mathrm{mg} / \mathrm{L} \mathrm{GO}$ exposure group (light blue bar), and $10 \mathrm{mg} / \mathrm{L}$ GO-exposure group (dark blue bar). Red metabolites are significant differential, black metabolites not identified in this study. 


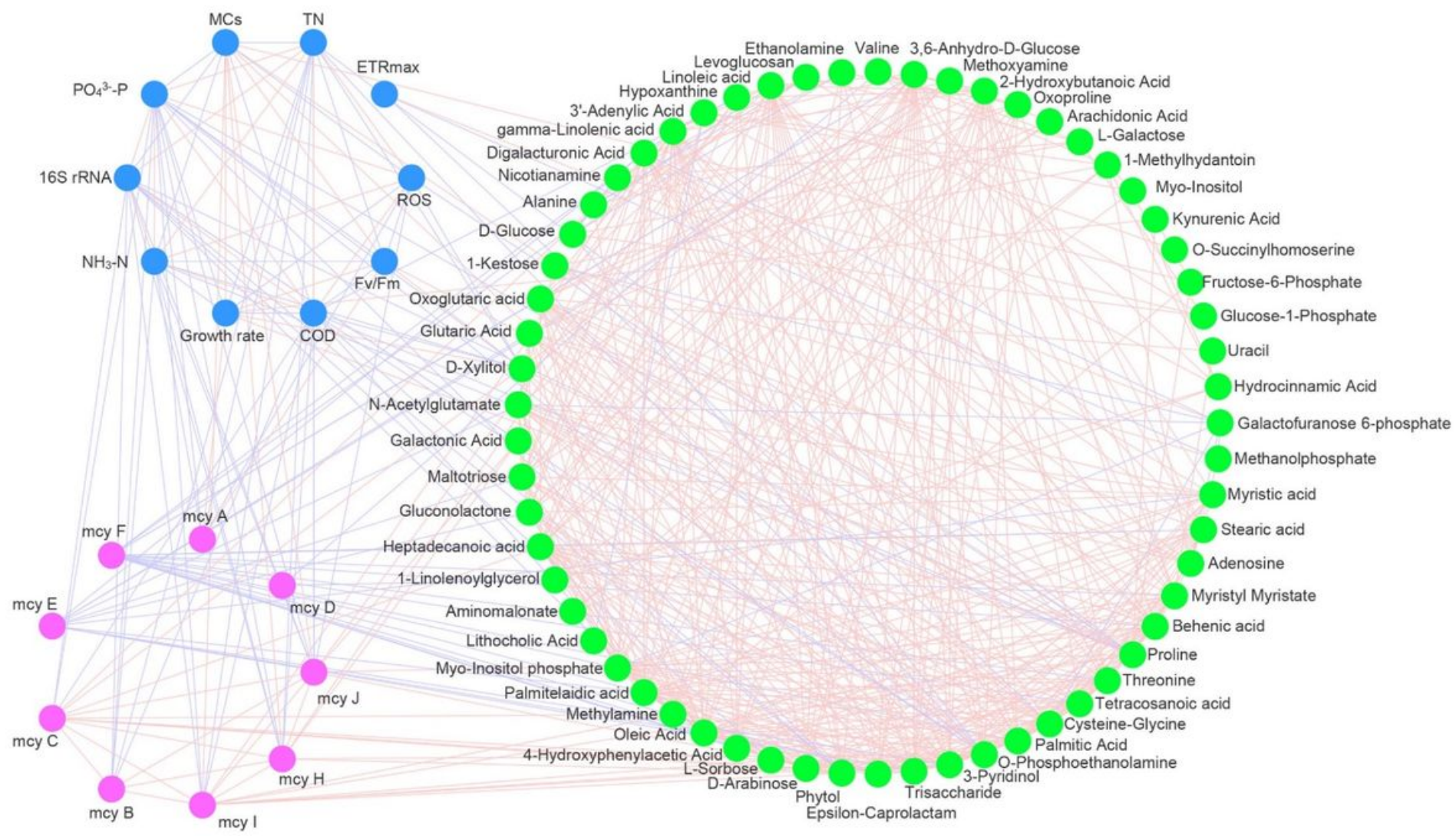

Figure 9

Pearson correlation network of metabolites (green), PO43--P, NH3-N, COD, ROS, Fv/Fm, ETRmax, growth rate, MCs, mcyA-J (red). The blue lines represent negative correlation coefficients, while red ones

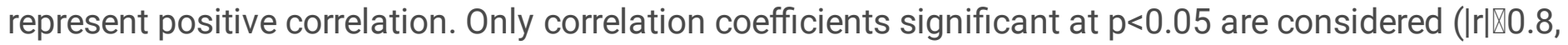
FDR $₫ 0.05)$.

\section{Supplementary Files}

This is a list of supplementary files associated with this preprint. Click to download.

- Supplementarymaterials.doc 